\section{Tratamento compulsório e internações psiquiátricas}

\section{Compulsory treatment and admission to psychiatric hospital}

Hildenete Monteiro Fortes 1
1 Programa de Doutoramento em Bioética. Faculdade de Medicina. Universidade do Porto. Alameda Prof. Hernâni Monteiro, 4200319. Porto, Portugal. E-mail: hmffnt@terra.com.br

\begin{abstract}
This article outlines the history of the various interpretations of madness. This provides an insight into the history of mental health, from initial mythical explanations to more rational modern approaches, from the tolerance of difference to its characterization as disease. The idea of treatable and possibly curable mental illnesses led to the emergence of psychiatric hospitals, which became symbols of incarceration and exclusion from society. Recurrent reports of violence and human rights abuses have, since the 1970s, fuelled calls to reform this model of psychiatric care and led to greater emphasis on care in the community, civil rights, and respect for the subjective and uniquely personal nature of mental illness. As a result, Brazilian law now recognizes the rights and duties both of the mentally ill and of the doctors who care for them, thereby ensuring respect for full human dignity, including the patient's right not to be subjected against his or her will to compulsory treatment.
\end{abstract}

Key words Mental health, Human rights, Commitment of Mentally Ill

\section{Resumo}

Este artigo traça um perfil histórico das diferentes interpretações da loucura, permitindo vislumbrar a própria história da saúde mental, desde seu caráter mítico inicial até explicações racionais, passando pela tolerância ao diferente até sua caracterização como doença. $\mathrm{Na}$ condição de doença mental, passivel de tratamento e possivel cura, surgem os hospitais psiquiátricos, os quais se tornaram símbolos da exclusão e seqüestro da cidadania. As recorrentes denúncias de violência e desrespeito aos direitos humanos, a partir da década de 1970, impulsionaram a reforma deste modelo de assistência psiquiátrica, pautando-se na desinstitucionalização e no resgate da cidadania e do respeito à singularidade e subjetividade do doente mental. A partir disso, a legislação brasileira passou a garantir os direitos e deveres tanto dos doentes mentais como dos médicos que deles cuidam, garantindo o respeito à dignidade humana em toda sua essência, inclusive no que tange a autonomia do paciente com relação ao tratamento compulsório.

Palavras-chave Saúde mental, Direitos humanos, Internação compulsória de doente mental 


\section{Introdução}

A conscientização de que as doenças mentais representam um sério problema de saúde pública é relativamente recente, se consolidando a partir de publicação realizada pela Organização Mundial da Saúde (OMS) e por pesquisadores da Escola de Saúde Pública da Universidade de Harvard, em 1994.1

As estimativas iniciais indicam que atualmente cerca de 450 milhões de pessoas no mundo sofrem de perturbações mentais, neurobiológicas ou, psicossociais, como de problemas relacionados com o abuso de álcool e drogas. A depressão grave é a principal causa de incapacitação; aproximadamente 70 milhões de pessoas sofrem de dependência do álcool; cerca de 50 milhões têm epilepsia e outros 24 milhões têm esquizofrenia. Dez a 20 milhões de pessoas tentam suicídio e um milhão anualmente cometem suicídio. Uma em cada quatro pessoas será afetada por uma doença mental em dada fase da vida. Os distúrbios mentais já representam quatro das dez principais causas de incapacidade em todo o mundo. ${ }^{2}$

Segundo dados do Ministério da Saúde 3 do Brasil é grande a magnitude epidemiológica dos transtornos mentais, com cuja prevalência nas cidades oscilando de $20 \%$ a $50 \%$.

Dentre os milhões de pessoas que sofrem de transtornos mentais ou comportamentais, apenas uma minoria tem tratamento, ainda assim elementar. Nos países em desenvolvimento a maioria das pessoas com problemas mentais graves tem a tarefa de resolver como podem seus problemas psicológicos. Em termos globais, transformam-se em vítimas por causa da sua doença e convertem-se em alvos de estigma e discriminação.

Elaborado há mais de meio século pela Organização Mundial da Saúde (OMS $)^{4}$ o conceito formal e pioneiro de saúde correspondente a um estado de completo bem-estar físico, mental e social que não se caracteriza unicamente pela ausência de doenças, e sim como um direito humano. Singer 5 considera que esta formulação inclui as circunstâncias econômicas, sociais e políticas, como também a discriminação social, religiosa ou sexual; e as restrições aos direitos humanos de ir e vir, e de exprimir livremente o pensamento. Este conceito considera como paradoxal o fato de alguém ser reconhecido com saúde mental, quando é afetado por pobreza extrema, discriminação ou repressão. Nas últimas décadas do século passado, os avanços tecnológicos e científicos, mostraram a necessidade de nova avaliação do conceito de saúde, que contemple a complexidade de conhecimento e condição humana como um todo. Isso torna cada vez mais evidente a necessidade de considerar o indivíduo não apenas como ser biológico complexo, mas também um ser essencialmente social, cujos valores são diversos, requerendo, na maioria das vezes, relações diferenciadas, sob a justa proteção do Estado e da sociedade. Sendo a saúde um direito universal do Homem, não se deve consolidar nenhum conceito de saúde que não expresse os princípios bioéticos de autonomia, beneficência e justiça.

A Constituição Brasileira ${ }^{6}$ amplia o conceito de saúde e as suas relações com o trabalho, moradia e ambiente. Com a criação do Sistema Único de Saúde (SUS) - conjunto de ações e serviços de saúde, prestados por órgãos e instituições públicas federais, estaduais e municipais, da administração direta e indireta e das fundações mantidas pelo poder público - a saúde passa a ser reconhecida como um direito de cidadania e dever do Estado. Baseado nos princípios da universalidade, equidade e integralidade e nas diretrizes de descentralização, regionalização e participação da comunidade, o SUS reafirma a saúde como um valor e um direito humano fundamental, legitimado pela justiça social. 7

A saúde mental assume diversas definições dependendo da cultura conforme os estudiosos que a ela se dedicam. De acordo com a OMS, 4 os conceitos de saúde mental abrangem entre outras coisas, o bem-estar subjetivo, a auto-eficácia percebida, a autonomia, a competência, a dependência intergeracional e a auto-realização do potencial intelectual e emocional da pessoa. Sendo assim, dificilmente se pode definir a saúde mental numa perspectiva transcultural. Contudo, há consenso quanto ao fato de que a saúde mental é algo mais do que a ausência de perturbações mentais. Uma compreensão completa do desenvolvimento das perturbações mentais e comportamentais se formará sobre a base da compreensão da saúde mental e, de um modo mais geral, o do funcionamento mental.

Nos últimos 25 anos, com o desenvolvimento de novos e eficientes psicofármacos, aliado aos programas interdisciplinares, houve um deslocamento do paciente do regime de internação para o regime ambulatorial e extra-hospitalar.

No entanto, deparamo-nos com situações clínicas em que a internação ainda hoje é uma medida prudente, mesmo imperativa, devendo o médico indicá-la, quando o agir do doente mental se manifestar em sentido inconscientemente prejudicial contra a vida ou a integridade física e moral do próprio ser ou da pessoa do outro, procedendo-a mediante o consentimento livre e esclarecido 
firmado pelo paciente, quando este se encontre capaz de ajuizar e deliberar sobre tal procedimento.

\section{A história da loucura e da saúde mental}

A história da saúde mental pode ser definida como a história das diversas interpretações da loucura que são levadas ao fim nas distintas épocas de acordo com os diferentes modelos vigentes de saúde naquele momento, tanto no que se refere a sua descrição e aplicação como em seu tratamento. ${ }^{8}$

A história da relação do ser humano com a loucura é, desde os primórdios da civilização, a história da tolerância para com a diferença entre as pessoas. A inserção da sua diferença numa perspectiva religiosa proporcionava ao louco um lugar contextualizado dentro da comunidade, fazendo com que a sua singularidade, ao invés de ser excluída, fosse assimilada como uma contribuição e não como uma subtração ao bem-estar comum. Dessa maneira, as sociedades ditas mais primitivas consideravam os indivíduos que apresentavam distúrbios mentais como emissários da divindade e assim portadores de poderes sobrenaturais. 9

Todo conhecimento que antes era voltado para o misticismo, passa por uma transição do pensamento mágico para causas naturais. São muitos os pensadores que começam a desenvolver explicações racionais para os transtornos mentais.

Hipócrates (460-380 a.C.), dotado de grande capacidade de observação, já associava quadros mentais a estados infecciosos, hemorragias e ao parto. Foi o primeiro a tentar libertar a medicina dos ritos mágicos. Para Hipócrates, o cérebro era a sede dos sentimentos e das idéias, tendo sido ele o pioneiro na classificação das doenças mentais. 10

O médico romano Galeno (131-200 d.C.), atribuía ao cérebro o papel controlador dos fenômenos mentais, "sede da alma", dividindo a alma em razão e intelecto, coragem e raiva, apetite carnal e desejos. 10

O período medieval veio se caracterizar por um retrocesso de todo pensamento científico a que se chegara até então. A feitiçaria e a "demonologia", justificativas da Inquisição, passaram a dominar o pensamento e as ações médicas neste período. A trajetória da intolerância para com os loucos, os mais frágeis e as mulheres tem na idade média o seu marco referencial.

A partir do século XVIII, o homem inventou uma nova maneira de se perceber. ${ }^{11}$ Com essa nova forma de vivenciar a condição humana, estabeleceu-se "o diferente", aquele que não segue o padrão de comportamento que a sociedade define. O doente mental, o excluído do convívio dos iguais, dos ditos normais, foi então afastado dos donos da razão, dos produtivos e dos que não ameaçavam a sociedade. Resende 12 refere que esses doentes, que podem desfrutar durante longo tempo de apreciável grau de tolerância social e de relativa liberdade, tiveram a liberdade cerceada junto a outros indivíduos ou grupos de indivíduos que, por não conseguirem ou não poderem adaptar-se a uma nova ordem social, passaram a ser vistos como uma ameaça a esta mesma ordem.

Na França do final do Século XVIII, no período que logo se seguiu à Revolução, Philippe Pinel (1755-1826) representou o marco inaugural do surgimento da Medicina Mental ou Psiquiatria, que transformou a diferença humana em patologia. Dessa maneira, a repercussão dessa apropriação da loucura pela ciência fez do louco um "doente" e da loucura uma doença a ser "tratada", no caso, com ocultamento e exclusão, com vistas a uma "cura". Além disso, baseado na compreensão de que a loucura era proveniente de uma lesão no cérebro e sob a influência do iluminismo, que pregava o zelo pela reforma social e elevação moral, considerou que as manifestações da loucura eram provenientes de um caráter mal formado e desenvolvido. ${ }^{9}$

O demônio criado pela Contra-Reforma finalmente saiu do corpo humano e a loucura tornou-se algo entendido como uma doença e assim passível de obter tratamento e cura. Partindo dessas referências, Pinel criou o Tratamento Moral, primeiro método terapêutico para a loucura na modernidade baseado em confinamentos, sangrias e purgativos e, finalmente, consagrou o hospital psiquiátrico, hospício ou manicômio como o lugar social dos loucos. ${ }^{9}$

A instituição psiquiátrica, construção do século XVIII tornou-se um emblema da exclusão e sequestro da cidadania e, até mesmo, da vida dos pacientes portadores de transtornos mentais, sendo que estava descomprometida com o cuidado à saúde e com a reinserção psicossocial. ${ }^{13}$

A psiquiatria moderna é impulsionada com idéias advindas do movimento romântico e começou a se manifestar uma nova proposição, que dizia existir outra dimensão (inconsciente) na condição humana. Sigmund Freud (1856-1939) foi o mentor de uma revolução intelectual na visão do homem pelo homem, com o desenvolvimento da teoria psicanalítica. Apesar da importante contribuição ao pensamento humano e à compreensão da loucura desenvolvida por Freud, ele não conseguiu romper com a referência mecanicista de seu tempo e o hospital psiquiátrico permanece como locus social 
dos loucos.

A exclusão e a submissão às regras do ainda presente hospício pineliano eram, por conseguinte, na prática, o único método "terapêutico" praticado.

No Brasil, a partir da segunda metade do século XIX, ainda durante o período imperial, tem início a assistência psiquiátrica pública, que era exercida de forma leiga mediante instituições de caráter asilar pertencentes à Igreja Católica. A sociedade do século XIX, sem muita diferença dos tempos atuais, via no louco uma ameaça à segurança pública, sendo o recolhimento aos asilos a única maneira de lidar com a pessoa com transtorno psiquiátrico. Esse recolhimento, autorizado e legitimado pelo Estado por meio de textos legais editados pelo Imperador, pretendia oferecer proteção à sociedade. A crescente pressão da população para o recolhimento dos alienados "inoportunos/as" a um lugar de isolamento fez com que o Estado Imperial determinasse a construção de um lugar específico com o objetivo de tratá-los. Nasceu assim o hospício Pedro II, em 1852, no Rio de Janeiro, com a função de remover e excluir o "elemento perturbador". De forma gradativa, esse modelo assistencial se desenvolveu e se ampliou em todo o território nacional, consolidando e reproduzindo no solo brasileiro o hospital psiquiátrico europeu como o espaço socialmente legitimado para a loucura.

Com a alteração da situação social e econômica que havia determinado o nascimento do hospício, o emergente capitalismo pedia novas providências. $\mathrm{O}$ processo político em curso, advindo da proclamação da República, resultou em novos confrontos de poder entre o Estado emergente, a classe médica, e a classe clerical. Este período foi configurado como o marco divisório entre a psiquiatria empírica e a psiquiatria científica. ${ }^{14}$ Até o final da década de 1950, tratar o doente mental continuava essencialmente restrito ao interior dos hospitais.

\section{A reforma da assistência psiquiátrica}

Ao longo do século XX buscou-se o desenvolvimento de outras formulações e modelos de assistência aos doentes mentais. A reforma da assistência psiquiátrica dá-se em razão do crescente clamor social causado pelas recorrentes denúncias de violência e outras variadas formas de desrespeito aos Direitos Humanos, gerando uma consciência crescente acerca da importância de se lutar pela preservação do direito à singularidade, à subjetividade e à diferença. 15

A partir da década de 1970 os movimentos de transformação da assistência psiquiátrica, iniciados após a Segunda Guerra Mundial, na Europa e nos Estados Unidos passaram a ter grande influência nos programas de saúde mental da América Latina e do Brasil. 16

Dentre os principais movimentos reformistas, de maior relevância, Pitta17 cita as comunidades terapêuticas e a antipsiquiatria na Inglaterra, o "setor" da política da França, o movimento de saúde mental comunitária nos Estados Unidos e a psiquiatria democrática italiana. $O$ psiquiatra italiano Franco Basaglia, 18 nos hospícios das cidades de Gorízia e depois Trieste, no norte da Itália, conseguiu superar o modelo asilar/carcerário herdado dos séculos anteriores e substituí-lo por uma rede diversificada de Serviços de Atenção Diária em Saúde Mental de Base Territorial e Comunitária. Finalmente o futuro tornou-se presente e o hospital pineliano passou a ser uma página virada da História.

No Brasil, até o início da década de 1980, o cenário da assistência psiquiátrica era crítico, caracterizado pela existência de cerca de 80 mil leitos psiquiátricos distribuídos em mais de 500 hospitais públicos e privados pelo país e que, amparado na ciência, produziu durante décadas um quadro aterrador de desassistência. 19 Em fins dos anos de 1970, quando as condições desumanas de vida e a falência ética e terapêutica nas instituições psiquiátricas tornaram-se uma realidade insuportável, foram finalmente denunciadas à sociedade por profissionais de saúde mental, que organizaram o Movimento de Trabalhadores de Saúde Mental (MTSM) no Rio de Janeiro, dando início ao processo que se convencionou chamar de reforma psiquiátrica. 20

A partir de então, a reforma psiquiátrica brasileira avançou significativamente como política pública, com o projeto de lei ${ }^{0} 3.65721$ - que dispõe sobre a extinção progressiva dos manicômios e sua substituição por outros recursos assistenciais e regulamenta a internação psiquiátrica compulsória dando início à progressiva mudança do modelo de atenção em saúde mental na década de 1990. O termo "reforma psiquiátrica" não deve ser entendido simplesmente como "desospitalização" e construção de um novo modelo ou sistema de atenção restrita ao campo da saúde mental e coletiva, como pode erroneamente parecer em um primeiro momento. Por reforma psiquiátrica entende-se um processo social e complexo, denominado de desinstitucionalização, que consiste em uma estratégia teórico-prática de desmontagem do conjunto de aparatos científicos, legislativos, administrativos, de códigos de referência e de relações de poder que se estruturam em torno do objeto doença. 22 
A reforma psiquiátrica, tomando como desafio a desinstitucionalização, tem sido discutida e entendida como uma variedade de conceitos e consequências. Delgado 23 afirma que a questão crucial da desinstitucionalização é uma progressiva devolução à comunidade da responsabilidade em relação aos seus doentes e aos seus conflitos. Para Birman, 24 trata-se de buscar outro lugar social para a loucura na nossa cultura. Assim, a indagação sobre outro lugar para a loucura põe em debate outro pólo da questão: a cidadania do doente mental. A constatação da amputação da dignidade humana, perda progressiva da auto-estima e da autonomia individual e coletiva, dos doentes mentais leva ao alijamento dos direitos de cidadania.

Segundo Amarante25 a reforma psiquiátrica defendida no Brasil, é fruto de um movimento histórico de caráter político, social e econômico, alcançada ao longo das últimas décadas, com maior conscientização da sociedade civil organizada.

Diversos setores das áreas de saúde pública e dos direitos humanos convergiram esforços na tentativa de ruptura, construindo, como proposta alternativa, a estruturação de uma rede de serviços de atenção diária em saúde mental de base territorial, integrando os usuários às suas respectivas famílias e à comunidade. 26

O que se espera da reforma psiquiátrica não é simplesmente a transferência do doente mental para fora dos muros do hospital, confinando-o à vida em casa, aos cuidados de quem puder assisti-lo ou entregue à própria sorte. Espera-se, muito mais, o resgate ou o estabelecimento da cidadania do doente mental, o respeito a sua singularidade e subjetividade, tornando-o sujeito de seu próprio tratamento sem a idéia de cura como o único horizonte. Esperase, assim, a autonomia e a reintegração do sujeito à família e à sociedade.

\section{Direitos humanos}

A dignidade da pessoa humana conforme dispõe o inciso III do artigo $1^{\circ}$ emerge como fundamento da Constituição da República Federativa Brasileira. ${ }^{6}$ Todos os profissionais que se ocupam de um paciente com transtorno mental deverão tratá-lo acima de tudo com humanidade e respeito. $\mathrm{Na}$ relação médico-paciente, o respeito do primeiro à autonomia do segundo representa o respeito à dignidade humana em toda a sua essência. A autonomia do indivíduo pressupõe a capacidade que têm as pessoas para a sua autodeterminação no que concerne às opções individuais de que dispõem.

Wachenfeld 27 relata que o marco no campo dos direitos das pessoas com doenças mentais foi a Assembléia Geral da Organizações das Nações Unidas (ONU) aprovar a resolução 46/119 de dezembro de 1991, sobre a proteção das pessoas com doenças mentais e a melhoria da assistência à saúde mental. A resolução 46/119 contém 25 princípios, vários dos quais subdivididos. Embora todos sejam igualmente importantes, vale mencionar alguns deles que adquirem particular importância no que concerne a questão dos direitos humanos. O Princípio $1^{\circ}$ parágrafo $(\S) 4^{\circ}$ estabelece que: "Não haverá discriminação sob alegação de transtorno mental. 'Discriminação' significa qualquer distinção, exclusão ou preferência que tenha o efeito de anular ou dificultar o desfrute igualitário de direitos." O mesmo Princípio segue especificando o direito de exercer todos os direitos civis, políticos, econômicos, sociais e culturais reconhecidos nos principais textos legais internacionais. $28 \mathrm{O}$ princípio $11^{\circ} \S 1^{\circ}$ estabelece que nenhum tratamento seja administrado a um usuário sem seu consentimento informado, o $\$ 8^{\circ}$ admite que exceto nas situações previstas o tratamento possa ser administrado a qualquer usuário sem o seu consentimento informado, se um profissional de saúde mental qualificado e autorizado por lei determinar que é urgentemente necessário, a fim de se evitar não maleficência ou iminente ao usuário ou a outras pessoas.

O Relatório sobre a Saúde no Mundo 20012 vem renovar a ênfase dada aos princípios proclamados, pela ONU, há uma década.

Um problema crucial em relação à questão dos direitos dos portadores de transtornos mentais é o anta-gonismo entre o enfoque da saúde pública e o dos direitos humanos.29 Enquanto o primeiro se preocupa prioritariamente com a maioria da população, opera em nível coletivo e privilegia a equidade, o segundo se preocupa fundamentalmente com a exceção, opera em nível individual e insiste em igualdade.

No Brasil dentre os instrumentos de proteção e defesa dos direitos humanos das pessoas com transtornos mentais, encontra-se a Lei Federal $10.216 / 2001,30$ a qual assimilou os princípios da Reforma Psiquiátrica: a centralidade da proteção dos direitos humanos e de cidadania das pessoas com transtornos mentais, a necessidade de construir redes de serviços que substituam o modelo hospitalocêntrico e a pactuação de ações por parte dos diferentes atores sociais. 31

\section{Legislação}

Em 1989, o deputado Paulo Delgado apresentou o 
projeto de lei $n^{\circ} 3.657 / 89,21$ que após mais de uma década tramitando no Congresso Nacional, foi aprovado e sancionado pelo Presidente da República, na Lei Federal 10.216.30 Essa lei destaca que as pessoas com transtornos mentais têm o direito conforme estabelecido no artigo $2^{\circ}$ parágrafo único, incisos I - ter acesso ao melhor tratamento do sistema de saúde, consentâneo às suas necessidades (principio da justiça); II - ser tratada com humanidade e respeito e no interesse exclusivo de beneficiar sua saúde, visando alcançar sua recuperação pela inserção na família, no trabalho e na comunidade (princípio da beneficência); V - ter direito à presença médica, em qualquer tempo, para esclarecer a necessidade ou não de sua hospitalização involuntária (princípios da justiça e autonomia); VII - receber o maior número de informações a respeito de sua doença e de seu tratamento (princípio da autonomia). Art. $4^{\circ} \mathrm{A}$ internação, em qualquer de suas modalidades, só será indicada quando os recursos extra-hospitalares se mostrarem insuficientes (princípio da beneficência). $\S 1^{\circ} \mathrm{O}$ tratamento visará, como finalidade permanente, a reinserção social do paciente em seu meio (princípio da não maleficência). No artigo $6^{\circ}$ estabelece que a internação psiquiátrica somente será realizada mediante laudo médico circunstanciado que caracterize os seus motivos. Parágrafo único. São considerados os seguintes tipos de internação psiquiátrica: I internação voluntária: aquela que se dá com o consentimento do usuário; II - internação involuntária: aquela que se dá sem o consentimento do usuário e a pedido de terceiro; e III - internação compulsória: aquela determinada pela Justiça. De acordo com o artigo $8^{\circ}$ a internação voluntária ou involuntária somente será autorizada por médicos devidamente registrados no Conselho Regional de Medicina (CRM) do Estado onde se localize o estabelecimento; parágrafo $1^{\circ}$ a internação psiquiátrica involuntária deverá, no prazo de setenta e duas horas, ser comunicada ao Ministério Público Estadual (MPE) pelo responsável técnico do estabelecimento no qual tenha ocorrido, devendo esse mesmo procedimento ser adotado quando da respectiva alta; parágrafo $2^{\circ}$ o término da internação involuntária dar-se-á por solicitação escrita do familiar, ou responsável legal, ou quando estabelecido pelo médico responsável pelo tratamento. $\mathrm{O}$ artigo $9^{\circ}$ refere-se a internação compulsória que é determinada, pelo juiz competente, que levará em conta as condições de segurança do estabelecimento, quanto à salvaguarda do paciente, dos demais internados $\mathrm{e}$ funcionários.

O Ministério da Saúde, através da Portaria $n^{\circ}$
2391,32 prevê quatro modalidades de internação: internação psiquiátrica voluntária (IPV), mediante consentimento livre e esclarecido; internação psiquiátrica involuntária (IPI), mediante comunicação ao MPE e a Comissão Revisora das Internações em até 72 horas; internação psiquiátrica voluntária que se torna involuntária (IPVI) quando o paciente internado exprimir sua discordância com a manutenção da internação, mediante comunicação ao MPE, em até 72 horas a partir de sua involuntariedade e internação psiquiátrica compulsória (IPC), mediante ordem judicial. O gestor estadual do SUS de acordo com essa portaria tem a responsabilidade em instaurar uma Comissão Revisora das Internações involuntárias, que faria o acompanhamento dessas internações, no prazo de sete dias após a comunicação.

O Conselho Federal de Medicina editou resoluções 33,34 condizentes com as obrigações internacionais na área dos direitos humanos, que servem de guia aos médicos do Brasil, sobre a internação e tratamento de pessoas com transtornos mentais à luz das normas nacionais e internacionais. De acordo com a Resolução CFM n ${ }^{\circ} 1.598 / 0033$ o Art. 15 - A internação de um paciente em um estabelecimento de assistência psiquiátrica pode ser de quatro modalidades: voluntária, involuntária, compulsória por motivo clínico e por ordem judicial, após processo regular. Parágrafo primeiro - A internação voluntária é feita de acordo com a vontade expressa do paciente em consentimento esclarecido, firmado pelo mesmo. Parágrafo segundo - A internação involuntária é realizada à margem da vontade do paciente, quando este não tem condições de consentir, mas não se opõe ao procedimento. Parágrafo terceiro - A internação compulsória por motivo clínico ocorre contrariando a vontade expressa do paciente, que recusa a medida terapêutica, por qualquer razão, este parágrafo foi revogado pela resolução $\mathrm{CFM} \mathrm{n}^{\mathrm{o}} 1.952 / 10.34$ Parágrafo quarto - A internação compulsória por decisão judicial resulta da decisão de um magistrado. Parágrafo quinto - No curso da internação, o paciente pode ter alteração na modalidade pela qual foi admitido originariamente.

O Código de Ética Médica35 nos capítulos de Direitos Humanos e Relação com pacientes e familiares são vedados aos médicos: "Art. 22. Deixar de obter consentimento do paciente ou de seu representante legal após esclarecê-lo sobre o procedimento a ser realizado, salvo em caso de risco iminente de morte." "Art. 24. Deixar de garantir ao paciente o exercício do direito de decidir livremente sobre sua pessoa ou seu bem-estar, bem como exercer sua autoridade para limitá-lo." “Art. 27. Desrespeitar a 
integridade física e mental do paciente ou utilizar-se de meio que possa alterar sua personalidade ou sua consciência em investigação policial ou de qualquer outra natureza." "Art. 28. Desrespeitar o interesse e a integridade do paciente em qualquer instituição na qual esteja recolhido, independentemente da própria vontade." "Art. 31. Desrespeitar o direito do paciente ou de seu representante legal de decidir livremente sobre a execução de práticas diagnósticas ou terapêuticas, salvo em caso de iminente risco de morte."

O Código de Ética Médica apresenta perfeita consonância com as disposições da ONU, de forma que trata da internação involuntária apenas nos casos em que o paciente oferece riscos para si ou para outrem, ou excepcionalmente, em caráter judicial.

\section{Internações psiquiátricas}

A prática médica, independentemente da especialidade, deve nortear-e pelos quatro princípios básicos da ética médica: o médico deve trabalhar visando unicamente os benefícios do paciente (beneficência); o médico deve evitar prejudicar o paciente (não maleficência); a independência do paciente deve ser respeitada (autonomia) e o médico deve evitar discriminação contra um paciente (justiça). 36

Uma das questões mais complexas da Psiquiatria diz respeito ao tratamento psiquiátrico involuntário, assim entendido aquele que ocorre sem o consentimento do paciente. De acordo com a Resolução CFM n ${ }^{\circ} 1.598 / 2000$ o artigo $6^{\circ}$ "Nenhum tratamento deve ser administrado a paciente psiquiátrico sem o seu consentimento esclarecido, salvo quando as condições clínicas não permitirem a obtenção desse consentimento, e em situações de emergência, caracterizadas e justificadas em prontuário, para evitar danos imediatos ou iminentes ao paciente ou a outras pessoas”. Parágrafo Único - Na impossibilidade de obter-se o consentimento esclarecido do paciente, e ressalvado as condições previstas no caput deste artigo, deve-se buscar o consentimento de um responsável legal.

A meta da internação é intervir na crise e controlá-la a fim de estabilizar os pacientes gravemente doentes e garantir a sua segurança e das outras pessoas. Uma vez determinada a necessidade de internação, é obrigação do médico informar ao paciente sobre a conduta proposta, garantindo ao mesmo o direito de livre arbítrio, mesmo que, supostamente, não compreenda o fato. Mesmo concordando com a internação, tal fato não deixa de se constituir em certo confinamento, podendo ferir a autonomia do paciente.
Autonomia é a capacidade de autogoverno, de livre arbítrio quanto à regência de seu próprio destino, envolve a proteção da privacidade, da confiabilidade e da procura de ações que se baseiam em um consentimento informado, opondo-se a qualquer forma de coerção, mesmo que seja justificada por eventuais benefícios sociais. ${ }^{37}$

Pode ocorrer um conflito de interesses entre médico e paciente, em que este se recusa a submeterse à indicação formulada por aquele. As internações voluntárias e involuntárias só poderão ser efetuadas mediante determinação do profissional de saúde mental qualificado e autorizado por lei, para este fim.

Consideram-se critérios técnicos para a internação involuntária, os direitos do paciente, a existência de um transtorno mental grave e o risco pessoal eminente ou de outrem e, critérios substantivos, a impossibilidade de tratamento em regime ambulatorial e a recusa ao tratamento proposto pelo médico. Nestas condições, o Estado confere ao médico psiquiatra, com o beneplácito da família ou responsável legal do paciente, a possibilidade da internação involuntária, mediante comunicação devidamente justificada ao Ministério Público Estadual, responsável pela fiscalização de tal procedimento, devendo utilizar o "Termo de Comunicação de Internação Psiquiátrica Involuntária.”. O doente mental pode ter sua capacidade reduzida, ou até mesmo nenhuma capacidade de expressar seu consentimento consciente e responsável, mas, por outro lado, de forma objetiva, sua vida ora em risco, deve ser igualmente protegida e sua saúde recuperada, pelo atendimento das suas necessidades.

O critério legal para definir capacidade tem como foco o entendimento do paciente sobre sua doença e suas conseqüências, os vários tratamentos disponíveis e seus riscos e benefícios, a credibilidade nas informações para que seja tomada uma decisão, por parte do indivíduo afetado pela doença que, obviamente, requer alguma habilidade intelectual. ${ }^{38}$ A competência é o equivalente clínico da capacidade. 39 Os fatores relevantes para julgar competência, principalmente em pacientes psiquiátricos, englobam uma série de variáveis que não estão incluídas nas definições legais de capacidade, como a interpretação das informações pelo indivíduo e a influência da doença mental sobre essa capacidade de interpretação. 40

Capacidade é o critério legal que indica ser um indivíduo capaz de tomar decisão autônoma e válida, já a competência neste contexto, refere-se ao conceito clínico de possuir habilidades para a tomada de decisões válidas em relação ao trata- 
mento. ${ }^{39}$ Em termo de assistência psiquiátrica, a capacidade ligada ao paciente, tendo um conceito fixo, usualmente ligado a aspectos legais, de estar habilitado para entender e assimilar informações relevantes para a decisão em questão e assim fazer uma escolha e a competência, substantiva, ligada a avaliação pelos profissionais de saúde, não é tão explícito em sua definição e inclui fatores adicionais de extrema importância no julgamento clínico, como consistência na expressão das decisões durante o tempo, consistência nas decisões expressas e razões subliminares por trás dessas, como desejos expressos anteriormente e a personalidade antes da doença, o estado emocional atual e seu impacto no processo da tomada de decisões, o impacto psicopatológico da doença mental nos sistemas de crenças, assim como nos sistemas de valores e desejos do paciente. ${ }^{41}$

Discute-se qual seria a maneira mais eficiente de proteger as pessoas portadoras de transtornos mentais em situações de ausência ou perda total ou parcial da plena capacidade psíquica e de autogoverno. Devemos considerar se é legítimo prover cuidado e proteção a quem é um risco para si ou para outros, mesmo quando esta atenção não é desejada, ou devemos respeitar a autonomia, quando isso possa implicar no aumento da vulnerabilidade destes pacientes?

Pode-se entender que as pessoas portadoras de transtornos mentais configuram-se como uma situação especial de vulnerabilidade, pelo menos em um determinado momento de seu quadro, quando tem a sua autonomia reduzida, o que sustenta o objetivo fundamental de proteger o bem maior que é sua própria vida.

O profissional da área de saúde mental torna-se, quase sempre, o único intérprete de seus pacientes, capaz de decidir, com aval dos familiares, sobre o futuro destas pessoas, exercendo muitas vezes poder absoluto sobre elas.

A internação involuntária, como o tratamento involuntário de uma forma geral, suscita uma série de questões éticas, devido à privação de liberdade do paciente, trazendo, inevitavelmente, um conflito entre dois dos princípios, exercidos na prática médica, a autonomia do paciente e a ação beneficente do paternalismo médico.

A comunicação da internação involuntária de um portador de transtorno mental ao Ministério Público Estadual servirá de proteção para o paciente de possíveis abusos por parte de terceiros, com ou sem anuência do médico assistente.

Por outro lado, as não intervenções e precauções terapêuticas aceitáveis, às quais o paciente tem direito, podem resultar em ação legal. O psiquiatra pode ser condenado no Código Penal42 e no Código de Ética Médica, ${ }^{35}$ caso seja constatada negligência, imprudência ou imperícia em seus diagnóstico e linha de tratamento, como por exemplo, não indicar uma internação involuntária, quando justificada técnica e legalmente.

A Internação Psiquiátrica Compulsória prevista na Lei 10.216 , artigo $4^{\circ}$ e parágrafo primeiro, aquela efetuada por determinação da autoridade judicial, quando o portador de transtorno mental oferece risco para si, para sua família ou para a sociedade, levando-se em conta as condições de segurança do estabelecimento, quanto à salvaguarda do paciente, dos demais internados e funcionários, por ser uma medida judicial, não podem ser legalmente questionados, embora sobre a ótica técnica e ético-moral, mereçam discussões profundas. Quaisquer que sejam as indicações das internações psiquiátricas, o Código Penal e a Lei Federal $n^{\circ} 10.216$ exigem que se dêem em estabelecimentos com características hospitalares, preservando a dignidade humana, garantindo ao paciente segurança e humanização no seu atendimento, com o mínimo possível de permanência, na unidade hospitalar e retorno ao convívio familiar e social.

\section{Considerações finais}

A civilização tem uma dívida com os portadores de transtornos mentais, desde que a Instituição Psiquiátrica, construção do século XVIII, produziu a exclusão e seqüestro da cidadania dos mesmos, pela criação de instituição de características asilares, sem preocupação com a re-inserção psicossocial.

O Brasil, copiando modelos externos, persistiu com as mesmas dívidas ao tratar a sua população portadora de transtorno mental, pela exclusão do convívio social, despojada de seus direitos, massacrada em sua subjetividade ao ser transformada em invisível no território de ninguém de uma institucionalização perversa, muitas vezes financiada com verbas públicas, em hospitais de características asilares, abrigos de idosos e outros.

Nos últimos anos observa-se um crescente reconhecimento da capacidade que as pessoas acometidas de transtornos mentais têm para desempenhar um papel mais ativo em relação a decisões sobre práticas e cuidados de saúde que as afetam direta ou indiretamente.

A atual lei da reforma psiquiátrica constitui um avanço na regulamentação de atos médicos envolvendo pacientes portadores de transtornos mentais, mas não basta por si mesma, fazendo-se necessária a fiscalização efetiva por parte do Ministério Público, 
das comissões de defesa dos Direitos Humanos e da sociedade como um todo, no que tange à regulação das internações involuntárias e compulsórias. O Ministério Público Estadual deve estabelecer rotinas de trabalho que facilitem a eficiente monitoração dos estabelecimentos que acatam internações psiquiátricas. A falta de sanção penal para os casos de descumprimento legal, quanto a não comunicação de internações involuntárias por parte da direção dos estabelecimentos clínicos, requer normatização legal específica.

A internação compulsória imposta ao paciente e ao médico assistente, nem sempre baseado em laudos ou avaliações de psiquiatras, leva preocupação aos profissionais médicos, por caracterizar a chamada judicialização de ato médico.

As instituições jurídicas passam a atuar e a interferir na área de saúde mental, de tal forma que atualmente, se constituem em uma via de acesso à internação psiquiátrica, causando desconforto aos médicos e desrespeito a autonomia do paciente, fra-

\section{Referências}

1. Lopez AD, Murray CC. The global burden of disease, 19902020. Nat Med. 1998; 4: 1241-3.

2. Organização Mundial da Saúde. Relatório sobre a saúde no mundo 2001. Saúde mental: nova concepção, nova esperança. Genebra; 2001.

3. Brasil. Ministério da Saúde. Por uma Política de Saúde Mental. Brasília, DF; 1999.

4. Organização Mundial da Saúde. Constituição da Organização Mundial da Saúde: adotada pela Conferência Internacional de Saúde. New York; 19 jul 1946.

5. Singer P. Prevenir e Curar. Rio de Janeiro: Forense Universitária; 1987.

6. Brasil. Constituição da República Federativa do Brasil de 1988. São Paulo: Editora Saraiva; 2000.

7. Lima JC. História das lutas sociais por saúde no Brasil. Trabalho necessário. 2006. [acesso em 23 Mai 2009] Disponível:http://www.uff.br/tabalhonecessario/Juliano\%2 0TN4.htm

8. Vidal G, Alarcón RD. Psiquiatria. Buenos Aires: Editorial Médica Panamericana; 1986.

9. Brasil. Ministério da Saúde. Secretaria de Gestão do Trabalho e da Educação na Saúde. Departamento de Gestão da Educação na Saúde. Direito sanitário e saúde pública. Brasília, DF; 2003: 135-69.

10. Cataldo Neto A, Annes S, Becker V. História da Psiquiatria In: Cataldo Neto A, Gauer GC, Furtado NR, coord. Psiquiatria para Estudantes de Medicina. Porto Alegre: EDIPUCRS; 2003.

11. Bezerra BJ. Saúde mental ou psiquiatria. Anais do IV Encontro de Pesquisadores em Saúde Mental e III Encontro de Especialistas em Enfermagem Psiquiátrica, 1995 abril 5- gilizando a relação entre estes.

As dificuldades de diálogo entre os atores envolvidos, no que concernem as situações de encaminhamentos judiciais para avaliação psiquiátrica e/ou internação, bem como à crescente intervenção do judiciário sobre os procedimentos clínicos dos profissionais de saúde mental, tem acarretado questões de natureza ética, moral e social, que merecem debates aprofundados das partes e busca de resoluções e parcerias consensuais visando o bem do paciente.

O estímulo ao diálogo entre os profissionais de saúde e o judiciário, por meio dos seus representantes médicos e juízes, respectivamente ou por meio das entidades de classes, com notas de esclarecimentos e informações, com orientações técnicas ou treinamentos, deverá ser o caminho em busca de um consenso, sem diminuir a responsabilidade e a respeitabilidade de cada um dos envolvidos, objetivando unicamente o bem estar do paciente.

7; Ribeirão Preto. São Paulo: Departamento de Enfermagem Psiquiátrica e Ciências Humanas da EERPUSP; 1995

12. Resende H. Política de saúde mental no Brasil: uma visão histórica. In: Bezerra BJ. Cidadania e loucura - Políticas de saúde mental no Brasil. Petrópolis: Vozes; 1987:1-73.

13. Foucault M. A história da loucura na Idade Clássica. São Paulo: Perspectiva; 1978.

14. Silva Filho JF. O sistema de saúde e a assistência psiquiátrica no Brasil. J Bras Psiquiatr. 1990; 39: 135-46.

15. Barros S, Egry EY. A enfermagem em saúde mental no Brasil: A necessidade de produção de novos conhecimentos. Saúde Soc. 1994; 3: 79-94.

16. Goulart MSB. A Construção da mudança nas instituições sociais: a reforma psiquiátrica. Pesq Prát Psicossociais. 2006; 1: 1-19.

17. Pitta HAM. Sobre urna política de saúde mental [dissertação]. São Paulo: Faculdade de Medicina da Universidade de São Paulo; 1984

18. Basaglia F. Em busca de necessidades perdidas. Rio de Janeiro: Civilização Brasileira; 1980.

19. Calicchio RR. Vinte anos de luta antimanicomial no Brasil: arte e comunicação como estratégia de participação e transformação social no contexto da reforma psiquiátrica. EcoPós. 2007; 10: 13-21.

20. Amarante P. Loucos pela vida: A trajetória da reforma psiquiátrica brasileira. 2 ed. Rio de Janeiro: Fiocruz; 1998.

21. Brasil. Projeto de Lei $\mathrm{n}^{\circ}$ 3.657, de 12 de setembro de 1989. Dispõe sobre a extinção progressiva dos manicômios e sua substituição por outros recursos assistenciais e regulamenta a internação psiquiátrica compulsória. Brasília, DF: Câmara 
dos Deputados; 1991.

22. Rotteli F, Leonardis O, Mauri D. Desinstitucionalização, uma outra via. In: Rotelli F, Leonardis O, Mauri D, orgs Desinstitucionalização. 2 ed. São Paulo: Hucitec; 2001. p.17-59

23. Delgado PGG. Perspectivas da psiquiatria pós-asilar no Brasil. In: Tundis SA, Costa NR, coordenadores. Cidadania e loucura: políticas de saúde mental no Brasil. Petrópolis: Vozes; 1987.

24. Birman JA. Cidadania tresloucada. In: Bezerra BJ, Amarante P. Psiquiatria sem hospício: contribuição ao estudo da reforma psiquiátrica. Rio de Janeiro: Editora Relume Dumará; 1992. p. 71-90.

25. Amarante P. O homem e a serpente: outras histórias para loucura e a psiquiatria. Rio de Janeiro: Fiocruz; 1996.

26. Farah MFS, Barboza HB. Novas experiências de gestão pública e cidadania. Rio de Janeiro: Editora FGV; 2000.

27. Wachenfeld $M$. The human rights of the mentally ill in Europe under the European Convention on Human Rights. Nord J Int Law. 1992; 109-292.

28. United Nations. Human rights: a compilation of international instruments. New York: United Nations; 1994.

29. Bertolote JM. The human rigths of the mentally ill in Europe under the European Convention on Human Rights. Int Dig Health Leg. 1994; 45: 618-620.

30. Brasil. Lei $\mathrm{n}^{\circ}$. 10.216, de 6 de abril de 2001. Dispõe sobre a proteção e os direitos das pessoas portadoras de transtornos mentais e redireciona o modelo assistencial em saúde mental. Diário Oficial da União [DOU]. Brasília, DF; 9 abr 2001.

31. Ribeiro PRM. Da psiquiatria à saúde mental: II - as renovações em psiquiatria e a ascensão das áreas afins. J Bras Psiquiatr. 1999; 48: 143-9.

32. Brasil. Portaria GM n 2.391, de 26 de Dezembro de 2002 Regulamenta o controle das internações psiquiátricas involuntárias (IPI) e voluntárias (IPV) e os procedimentos de notificação da Comunicação das IPI e IPV ao Ministério Público pelos estabelecimentos de saúde, integrantes ou não do SUS. Diário Oficial da União. Brasília, DF. n.250, p 349-50, 27 dez. 2002. Seção 1.

Recebido em 13 de maio de 2010

Versão final apresentada em 29 de outubro de 2010

Aprovado em 1 de dezembro de 2010
33. Brasil. Conselho Federal de Medicina. Resolução $n^{\circ} 1.598$, de 09 de agosto de 2000. Normatiza o atendimento médico a pacientes portadores de transtorno mental. Diário Oficial da União [DOU]. Brasília, DF.p.63,18 ago 2000.Seção 1.

34. Brasil. Conselho Federal de Medicina. Resolução nº 1952, de 07 de julho de 2010. Adota as diretrizes para um modelo de assistência integral em saúde mental no Brasil e modifica a Resolução CFM n ${ }^{0}$ 1.598. Diário Oficial da União [DOU]. Brasília, DF, 07 jul 2010. p. 133.

35. Brasil. Conselho Federal de Medicina. Resolução $n^{\circ} 1.931$, de 17 de setembro de 2009. Código de Ética Médica. Diário Oficial da União. Brasília, DF. p. 173, 13 out. 2009. Seção

36. Beauchamp TL, Childress JF. Principles of Biomedical Ethics. 4 ed.New York: Oxford; 1994. p. 100-3.

37. Marcolino JAM. Psiquiatria e psicoterapia no âmbito institucional. In: Alves LCA, coordenador. Ética e psiquiatria. São Paulo: Conselho Regional de Medicina do Estado de São Paulo; 2007:72.

38. British Medical Association. Assessment of mental capacity: guidance for doctors and lawyers. A report of the British Medical Association and The Law Society. London; 1995: 65-6

39. Tan JOA, Jones DPH. Children's consent. Curr Opin Psychiatry 2001; 14: 303-7.

40. Grisso T, Appelbaum PS. Assessing competence to consent to treatment: a guide for physicians and other health professionals. Oxford: Oxford University Press; 1998. p. 173-200.

41. Tan JOA, Hope T, Stewart A. Anorexia nervosa and personal identity: the accounts of patients and their parents. Int J Law Psychiatry. 2003; 26: 535-48.

42. Código de processo penal interpretado. 9 ed. São Paulo: Editora Atlas; 2002. 